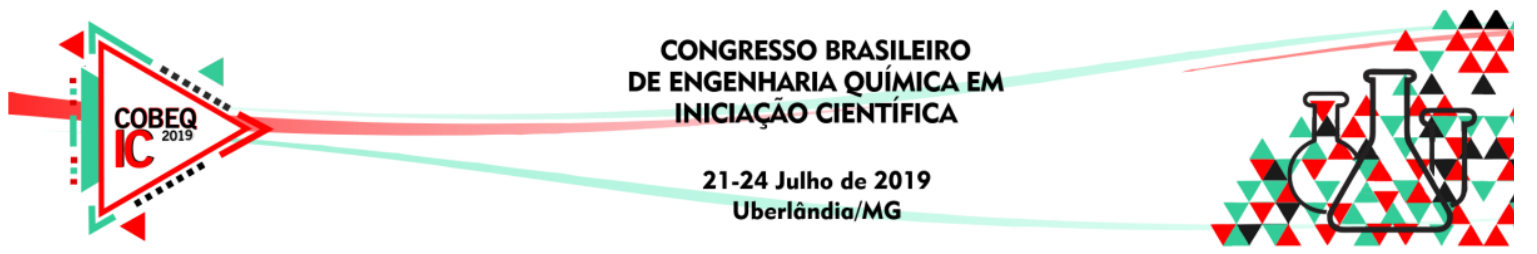

\title{
PREPARO DOS FRUTOS DA PIMENTA ROSA PARA SECAGEM POR CAST-TAPE DRYING
}

\author{
E.L.A. BATISTA ${ }^{1}$, R.C. SILVA ${ }^{1}$, L. S. OLIVEIRA ${ }^{1}$, R.C. PICH $^{1}$ e L.R. GUIDI ${ }^{1}$ \\ ${ }^{1}$ Universidade Federal de Uberlândia, Engenharia de Alimentos \\ E-mail para contato: leticiaguidi@ufu.br
}

\begin{abstract}
RESUMO - A pimenta rosa, é uma planta reconhecida por ter apelo medicinal e pela aplicação como condimento. Com o intuito de preservar as características nutricionais, funcionais e sensoriais desse produto, as indústrias têm grande interesse em aplicar métodos para conservação do mesmo. Neste sentido, a secagem por cast-tape drying tem se mostrado uma alternativa viável para a desidratação de alimentos com preservação dessas características. O objetivo deste trabalho é apresentar uma metodologia adequada de preparo da pimenta rosa antes de submetê-las à secagem por cast-tape drying.
\end{abstract}

\section{INTRODUÇÃO}

Os frutos da pimenta rosa (Schinus terebinthifolius Raddi) possuem reconhecimento e apelo medicinal, sendo utilizada para tratar condições inflamatórias, feridas na pele, úlceras, problemas respiratórios, infecções urinárias e artrite (Rosas et al., 2015). Eles são utilizados como um condimento alimentar com crescente demanda, por conferir sabor característico. Esses frutos quando recém-colhidos apresentam umidade, atividade de água e concentração de substratos elevadas, o que pode favorecer a ação das enzimas e levar a alterações fisiológicas, tendo como consequências a perda de princípios ativos e de compostos voláteis, além das alterações de cor e textura. Portanto, para garantir qualidade sensorial e microbiológica dos desses frutos, a desidratação deve ser realizada para sua comercialização (Bertoldi, 2006).

A secagem por cast-tape drying (CTD) tem ganhado destaque para desidratar alimentos, pois retém pigmentos e compostos aromáticos ativos responsáveis pelas características nutricionais, funcionais e sensoriais, utilizando temperaturas de secagem abaixo do ponto de ebulição da água e tempos de secagem relativamente curtos (Raghavi et al., 2018). Nesse método, o alimento, geralmente na forma de pasta, é espalhado na face superior de um suporte polimérico, e aquecido, usualmente por água quente, em sua face inferior. Assim, a energia térmica é transferida para o material úmido espalhado sobre o filme polimérico. É um processo relativamente recente e, uma vez que a pasta precisa ter a consistência certa para ser espalhada uniformemente, a metodologia mais adequada de preparo da amostra para espalhamento sobre o filme polimérico precisa ser investigada.

Não foram encontrados na literatura trabalhos que descreveram a secagem da pimenta rosa por cast-tape drying. Desta forma, o objetivo deste trabalho foi estabelecer a metodologia de preparo (redução de tamanho e transformação em material com consistência de pasta) da pimenta rosa para secagem por cast-tape drying. 


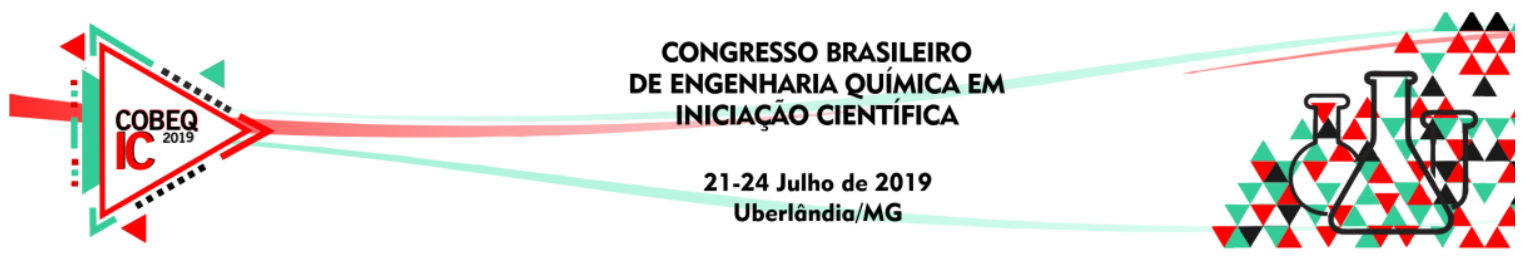

\section{MATERIAL E MÉTODOS}

\subsection{Coleta e armazenamento das amostras}

As amostras dos frutos maduros de pimenta rosa foram provenientes de árvores situadas em Patos de Minas-MG. Após a colheita, os frutos foram limpos, removendo-se folhas, restos de galhos e demais sujidades. Em seguida, as pimentas foram lavadas e secas com auxílio de papel toalha e então acondicionadas em embalagens e estocadas em ultrafreezer (Indrel, modelo IULT335D, Brasil) a temperatura de $-60{ }^{\circ} \mathrm{C}$. Previamente ao uso, as amostras foram descongeladas em geladeira na temperatura entre 6 e $10{ }^{\circ} \mathrm{C}$ (Consul, Brasil) durante $24 \mathrm{~h}$.

\subsection{Preparo das amostras}

As metodologias de redução de tamanho dos frutos para obtenção da pimenta rosa desidratada avaliadas foram: moagem em moinho de facas (Fortinox, modelo Star FC 50, Brasil); e, trituração em liquidificador industrial (Camargo, Brasil). Em ambas as metodologias, as temperaturas das amostras foram medidas antes e após a redução de tamanho com termômetro de mercúrio escala -10 a $110{ }^{\circ} \mathrm{C}$ (Incotherm, Brasil).

Com o objetivo de obter uma pasta que proporcionasse o espalhamento de uma camada com espessura uniforme sobre o filme do equipamento, os frutos triturados de pimenta rosa in natura foram submetidos à diluição com água destilada, nos seguintes percentuais em peso: adição de 0 \% e 40 \% de água em relação à massa total de pimenta.

\subsection{Unidade experimental utilizada para a secagem por cast-tape drying}

$\mathrm{Na}$ secagem por cast-tape drying, em batelada, foi utilizado um equipamento montado em um laboratório do curso de Engenharia de Alimentos da Universidade Federal de Uberlândia, campus Patos de Minas. A unidade experimental foi composta de um reservatório (bandeja de 0,7 m x 0,3 m x 0,05 m). O filme polimérico, mylar ${ }^{\circledR}$ (Dupont, USA) de 0,25 mm de espessura, foi fixado no topo da bandeja de forma que a face inferior ficasse em contato com a água quente circulante e a superior servisse de suporte para a pasta de pimenta rosa.

\subsection{Determinação da cinética de secagem por cast-tape drying}

A cinética de secagem foi determinada por meio da retirada de amostras em triplicata de pontos distintos da parte central da pasta espalhada sobre o filme mylar ${ }^{\circledR}$. As condições experimentais fixadas na secagem foram: temperatura da água do banho de $95^{\circ} \mathrm{C}$ e espessura de espalhamento da pasta de $2 \mathrm{~mm}$.

A umidade das amostras foi determinada segundo a metodologia A.O.A.C. (2005), sendo que, todas as análises foram realizadas em triplicata.

\subsection{Análise granulométrica}

A distribuição granulométrica das amostras secas foi obtida por peneiramento, utilizando um conjunto de peneiras da série Tyler. O diâmetro médio de Sauter das partículas foi calculado conforme a Equação 1, na qual $\bar{D}$ é o diâmetro médio de Sauter, $\Delta x_{i}$ é a fração em massa retida 


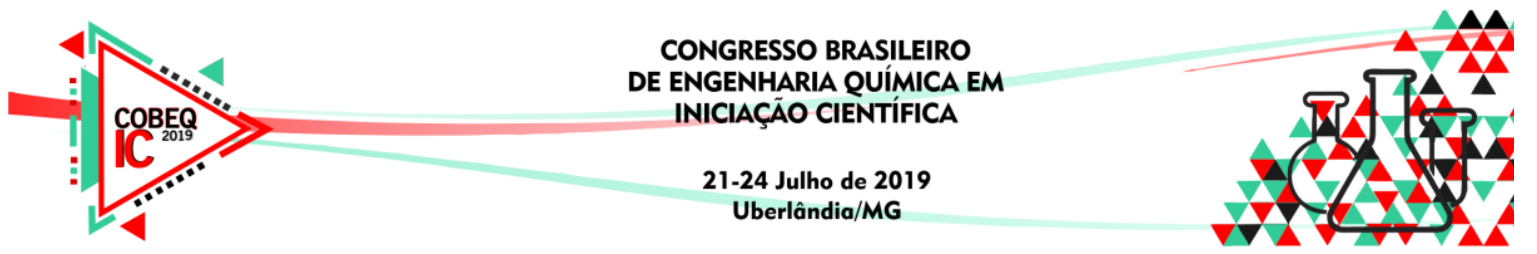

em cada faixa e $D_{i}$ é o diâmetro médio em cada faixa da distribuição. Com os resultados da distribuição granulométrica testaram-se os modelos clássicos de distribuição a 2 parâmetros, verificando qual o que melhor se ajusta para cada amostra.

$$
\bar{D}=1 / \sum_{i} \frac{\Delta x_{i}}{D_{i}}
$$

\section{RESULTADOS E DISCUSSÕES}

\subsection{Redução de tamanho dos frutos de pimenta rosa}

Os resultados de temperatura das amostras antes e após a redução de tamanho e umidade após a redução de tamanho, são apresentados na Tabela 1. Na Figura 1 são mostradas fotografias das amostras submetidas à redução de tamanho.

Tabela 1 - Variação de temperatura e umidade final das amostras de pimenta rosa de acordo com a metodologia de redução de tamanho.

\begin{tabular}{cccc}
\hline $\begin{array}{c}\text { Equipamento } \\
\text { utilizado para } \\
\text { redução de tamanho }\end{array}$ & $\begin{array}{c}\text { Temperatura da amostra } \\
\text { antes da redução de } \\
\text { tamanho }\left({ }^{\circ} \mathbf{C}\right)\end{array}$ & $\begin{array}{c}\text { Temperatura da } \\
\text { amostra após redução } \\
\text { de tamanho }\left({ }^{\circ} \mathbf{C}\right)\end{array}$ & $\begin{array}{c}\text { Umidade } \\
\text { da amostra } \\
\text { (g/g b.s. })\end{array}$ \\
\hline $\begin{array}{c}\text { Liquidificador } \\
\text { Industrial }\end{array}$ & 24 & 33 & $0,522 \pm$ \\
& 24 & 39 & 0,010 \\
\hline Moinho de Facas & 24 & $0,454 \pm$ \\
\end{tabular}

Figura 1 - Pimenta rosa após a redução de tamanho: a) liquidificador; b) moinho de facas.

a)

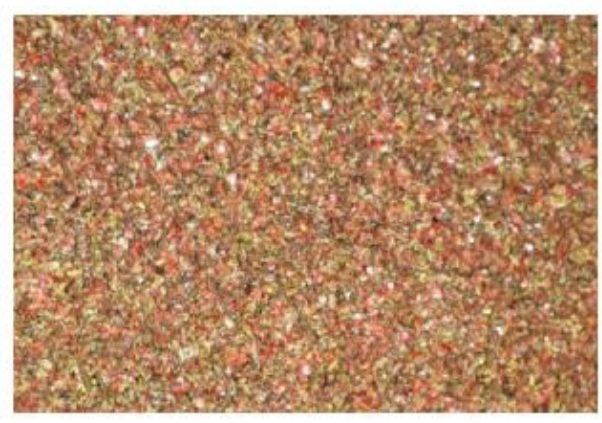

b)

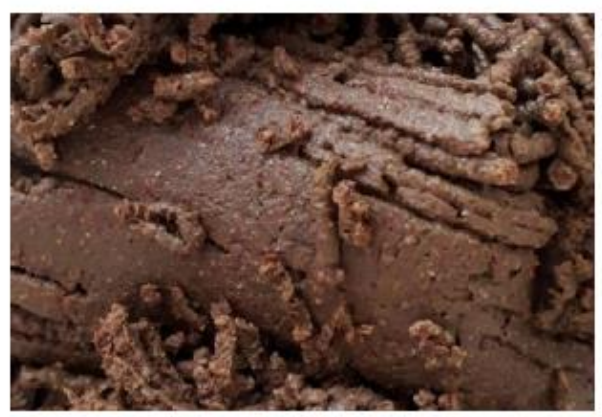

De acordo com os resultados da Tabela 1, foi possível verificar que o aumento da temperatura das amostras após a redução de tamanho em moinho de facas (de 24 para $39{ }^{\circ} \mathrm{C}$ ), bem como a redução na umidade, observada qualitativamente no momento da moagem pela formação de névoa na saída do moinho, alterou as características de umidade iniciais da amostra. As alterações na umidade das amostras provavelmente se devem à remoção mecânica de água, uma vez que ocorre a prensagem do material no interior do equipamento e ao início do processo de desidratação devido à elevação da temperatura da amostra.

Foram percebidas alterações de cor (conforme Figura 1), provavelmente, devido ao escurecimento enzimático em resposta aos danos físicos e físiológicos provocados pelo impacto e abrasão na etapa de moagem, como resultado da oxidação de compostos fenólicos presentes 


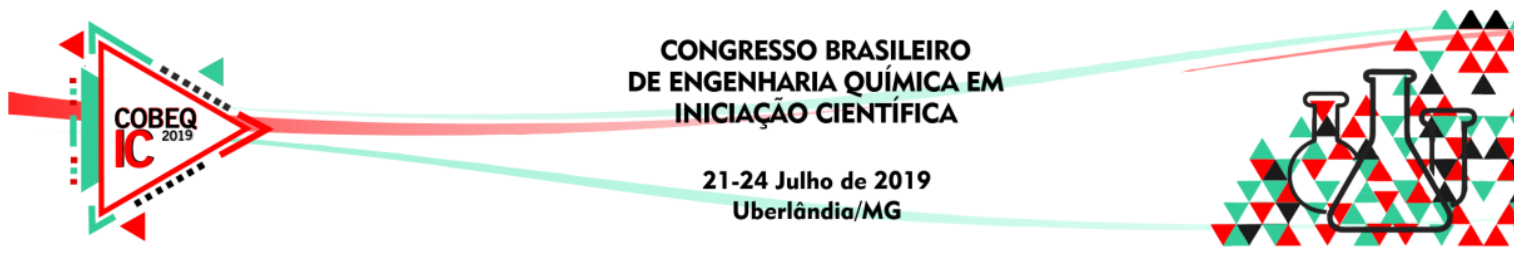

na pimenta rosa. $\mathrm{O}$ escurecimento enzimático é causado principalmente pela ação da enzima polifenol oxidase (PPO) na presença do oxigênio atmosférico (Alvarez et al., 2011). Portanto, seria interessante estudar uma etapa prévia de branqueamento da amostra.

\subsection{Distribuição granulométrica e cinética de secagem}

Na Tabela 2 estão apresentados os resultados para o diâmetro de Sauter, e para os modelos de distribuição de tamanho que melhor se ajustaram aos dados. Para a amostra submetida à redução de tamanho em liquidificador industrial o melhor modelo foi o RosinRammler-Bennett (RRB) (Equação 2) e para a amostra moída em moinho de facas, o melhor ajuste foi do modelo Sigmoide (Equação 3), sendo que, em ambos, $d_{p}$ é tamanho de partícula e $X$ é a fração cumulativa.

Tabela 2 - Diâmetro médio de Sauter e resultado da regressão para o ajuste dos modelos.

\begin{tabular}{ccccc}
\hline Método de & Diâmetro & \multicolumn{3}{c}{ Modelo de distribuição de tamanho de partícula } \\
\cline { 3 - 5 } $\begin{array}{c}\text { redução de } \\
\text { tamanho }\end{array}$ & $\begin{array}{c}\text { médio de } \\
\text { Sauter }(\mathbf{m m})\end{array}$ & Equação & Parâmetros & $\mathbf{R}^{\mathbf{2}}$ \\
\hline $\begin{array}{c}\text { Liquidificador } \\
\text { Industrial }\end{array}$ & $\begin{array}{c}0,0200 \pm \\
0,0003\end{array}$ & $X=1-\exp \left[-\left(\frac{d_{p}}{d_{63,2}}\right)^{n}\right]$ & $\begin{array}{c}(2) \\
\mathrm{d}_{63,2}=0,638 \mathrm{~mm} \\
\mathrm{n}=1,92\end{array}$ & 0,9936 \\
\hline $\begin{array}{c}\text { Moinho de } \\
\text { Facas }\end{array}$ & $\begin{array}{c}0,0144 \pm \\
0,0004\end{array}$ & $X=\frac{1}{1+\left(\frac{d_{50}}{d_{p}}\right)^{p}}$ & $\begin{array}{c}(3) \\
\mathrm{d}_{50}=0,235 \mathrm{~mm} \\
\mathrm{p}=3,83\end{array}$ & 0,9912 \\
\hline
\end{tabular}

A distribuição granulométrica apresentada na Figura 2 mostra que a amostra obtida no liquidificador industrial é mais heterogênea no que diz respeito ao tamanho de partícula, isto é, apresenta uma distribuição granulométrica mais ampla, resultando também em maior tamanho médio de partícula. Já as amostras submetidas ao moinho de facas têm uma distribuição de tamanho de partícula mais uniforme, numa faixa mais estreita, apresentando menor tamanho de partícula (conforme observado nos valores dos diâmetros médios de Sauter na Tabela 2).

Figura 2 - Distribuição granulométrica das amostras de pimenta rosa após secagem por CTD.

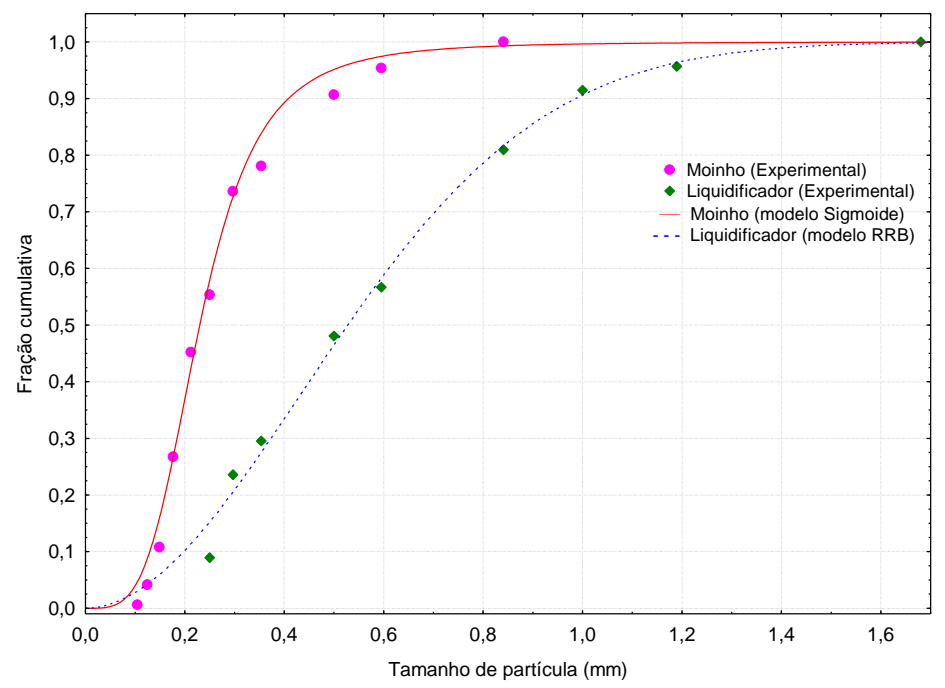




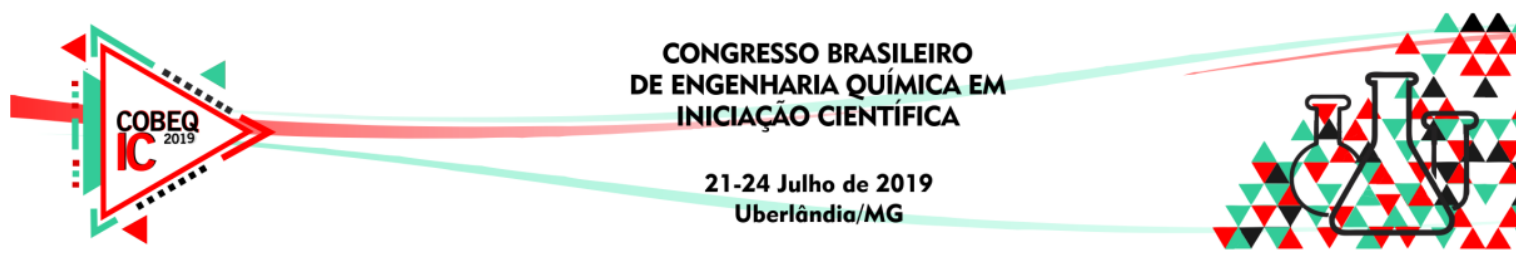

\subsection{Preparo dos frutos triturados de pimenta rosa para secagem}

No que diz respeito ao espalhamento, a amostra com adição de água de $40 \%$, em peso, conduziu a uma pasta com consistência e escoabilidade mais satisfatórias. Por isso, essa concentração foi eleita para a utilização nos experimentos posteriores. Embora a adição de água possa significar um maior tempo de operação, o melhor espalhamento (sobre o filme) da amostra a ser seca resulta em um produto seco com características mais uniformes.

$\mathrm{Na}$ Tabela 3 são apresentadas as umidades iniciais das amostras adicionadas de $0 \% \mathrm{e}$ $40 \%$ em peso de água.

Tabela 3 - Umidades iniciais das amostras após a adição de água.

\begin{tabular}{ccc}
\hline $\begin{array}{c}\text { Quantidade de água } \\
\text { adicionada }(\% \text { em peso) }\end{array}$ & $\begin{array}{c}\text { Metodologia de } \\
\text { Redução de Tamanho }\end{array}$ & $\begin{array}{c}\text { Umidade da } \\
\text { amostra } \\
(\mathbf{g} / \mathbf{g} \text { b.s. })\end{array}$ \\
\hline 0 & Liquidificador & $0,522 \pm 0,010$ \\
40 & Industrial & $1,538 \pm 0,037$ \\
\hline 0 & Moinho de Facas & $0,454 \pm 0,006$ \\
40 & $1,442 \pm 0,029$ \\
\hline
\end{tabular}

A partir dos resultados apresentados na Tabela 3 ratifica-se os resultados encontrados para umidade inicial das amostras após a redução de tamanho (Tabela 1), demonstrando que a metodologia de redução de tamanho interferiu na umidade inicial das amostras (que afeta a obtenção da pasta) e a adição de água às mesmas manteve estas interferências.

\subsection{Cinética de secagem}

A partir dos testes para obtenção de uma polpa com melhor consistência para espalhamento, a secagem por CTD foi realizada para as amostras produzidas pelas duas metodologias de redução de tamanho. Na Figura 3 estão apresentadas as curvas de secagem das amostras de pimenta rosa, moída em moinho de facas e triturada em liquidificador industrial, secas por CTD à temperatura de $95^{\circ} \mathrm{C}$ (água circulante), espessura da pasta dos frutos de $2 \mathrm{~mm}$ e com adição de $40 \%$ em peso de água.

Figura 3 - Curvas de secagem da pimenta rosa submetidas à secagem por cast-tape drying a $95{ }^{\circ} \mathrm{C}, 2 \mathrm{~mm}$ de espessura e $40 \%$ de água em peso na amostra.

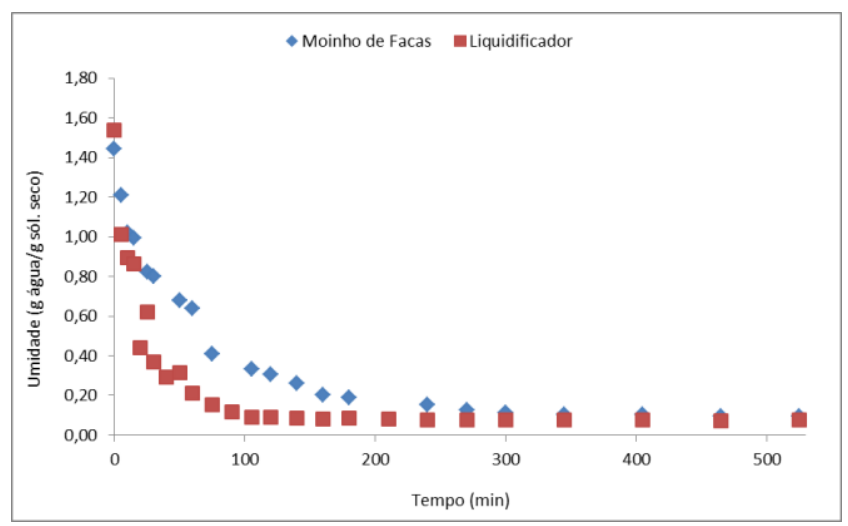




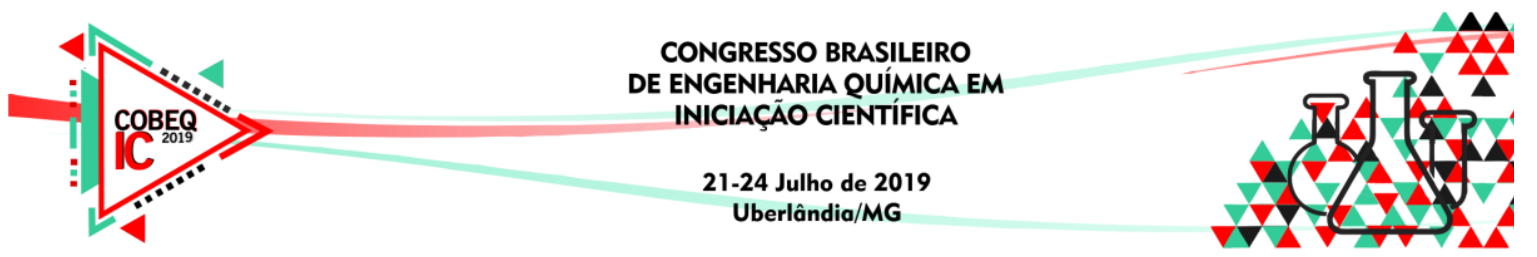

Analisando a Figura 3, foi possível verificar que o tempo de secagem para atingir a umidade de equilíbrio da amostra moída em moinho de facas foi maior do que da amostra moída em liquidificador industrial, o que indica que o menor tamanho de partícula da amostra interferiu na cinética de secagem, cerca de 200 min maior. Durante os experimentos foi possível observar que para a amostra moída em moinho de facas, embora a amostra seja mais homogênea, a parte inferior da amostra em contato com o filme mylar ${ }^{\circledR}$ apresentou aspecto mais compacto (como uma placa), com menor friabilidade e maior dureza que a moída em liquidificador industrial, indicando que esta formação compacta interferiu no fluxo de calor e massa para a superfície do sólido durante a secagem, resultando no maior tempo de secagem.

\section{CONCLUSÃO}

A redução de tamanho dos frutos de pimenta rosa foi possível nas duas metodologias empregadas. Entretanto, a metodologia que melhor preservou a umidade dos frutos in natura durante a etapa de redução de tamanho e que apresentou a menor elevação de temperatura da amostra foi a trituração realizada no liquidificador industrial. Nestas condições, para que as amostras atingissem a consistência de pasta que permitisse o espalhamento foi necessária a adição de $40 \%$ de água às amostras após a redução de tamanho. A secagem dos frutos de pimenta rosa foi possível por cast-tape drying, sendo que, nas condições de secagem estabelecidas (temperatura da água circulante de $95^{\circ} \mathrm{C}$ e espessura de espalhamento de $2 \mathrm{~mm}$ ), a amostra triturada em liquidificador industrial foi a que apresentou menor tempo para atingir a umidade de equilíbrio e produziu um produto seco com menor alteração da característica cor.

\section{AGRADECIMENTOS}

Agradecimento a PROGRAD e ao CNPq pelo auxílio financeiro.

\section{REFERÊNCIAS}

ALVAREZ, L. D.; FLORES, E. J.; GONZALEZ, K.; MARTINEZ, R.; PARADA, L Blanching peppers using microwaves. Procedia Food Science, v. 1, p. 178-183, 2011.

BERTOLDI, M.C. Atividade antioxidante in vitro da fração fenólica, das oleorresinas e do óleo essencial de pimenta rosa (Schinus terebinthifolius raddi). Tese apresentada à Universidade Federal de Viçosa, como parte das exigências do Programa de PósGraduação em Ciência e Tecnologia de Alimentos. (2006). 96p.

RAGHAVI, L. M.; MOSES, J. A.; ANANDHARAMAKRISHNAN, C. Refractance window drying of foods: A review. Journal of Food Engineering, v. 222, p. 267-275, 2018.

ROSAS, E.C.; CORREA, L. B.; PÁDUA, T. A.; COSTA, T. E. M. M.; MAZZEI, J. L.; HERINGER, A. P.; BIZARRO, C. A.; KAPLAN, M. A.; FIGUEIREDO, M. R.; HENRIQUES, M. G. Anti-inflammatory effect of Schinus terebinthifolius Raddi hydroalcoholic extract on neutrophil migration in zymosan-induced arthritis. Journal of Ethnopharmacology, 175 (2015) 490-498. 